\title{
JOB MIX LASTON (AC-BC) MENGGUNAKAN BUBUK GYPSUM DAN ABU BATA MERAH
}

\author{
${ }^{1 *}$ Moch. Aminuddin, ${ }^{2}$ Agata Iwan Candra, ${ }^{3}$ Yosef Cahyo S \\ Fakultas Teknik Universitas Kadiri \\ e-mail: ${ }^{1 *}$ moch.aminuddin06@gmail.com, ${ }^{2}$ iwan agata@ unik-kediri.ac.id, ${ }^{3}$ yosef.cs@unik- \\ kediri.ac.id
}

\begin{abstract}
In a mixture of laston filler serves as a cavity filler in the mixture, increases stability, and binders concrete asphalt. In this study, researchers used gypsum powder and red brick ash filler instead of cement. This research was conducted to find out how the effect of using gypsum and red brick ash powder as filler in the laston mixture $(a c-b c)$ in terms of Marshall characteristics. Variations in the asphalt content used in the laston mixture in this study were 5\%, 5.5\%, 6\%, 6.5\%, and 7\% in which each bitumen content was made as many as 3 samples. After doing the Marshall test, it is known that with volumetric and Marshall parameters using 3 samples of each bitumen content, the average results obtained in the calculation: VMA of $17.68 \%$, VIM of $4.46 \%$, VFB of $74.87 \%$, Stability amounting to $1152 \mathrm{~kg}$, Flow of $2.47 \mathrm{~mm}$, and $M Q$ of $472 \mathrm{~kg} / \mathrm{mm}$. And from the results of tests or testing of Marshall characteristics, the optimum bitumen content needed in the last-mix mixture of $A C-B C$ using powdered gypsum and red brick ash filler was $6.5 \%$.
\end{abstract}

Keywords : Laston, Filler, Gypsum Powder, Red Brick Ash, Marshall Characteristics

\begin{abstract}
Abstrak
Dalam campuran laston filler berfungsi sebagai bahan pengisi rongga di dalam campuran, meningkatkan stabilitas, dan pengikat aspal beton. Pada penelitian ini, peneliti menggunakan filler bubuk gypsum dan abu bata merah sebagai pengganti semen. Penelitian ini dilakukan untuk mengetahui bagaimana pengaruh penggunaan bubuk gypsum dan abu bata merah sebagai filler dalam campuran laston (ac-bc) yang ditinjau dari karakteristik Marshall. Variasi kadar aspal yang digunakan dalam campuran lastonpada penelitian ini adalah $5 \%, 5,5 \%, 6 \%, 6,5 \%$, dan $7 \%$ yang mana setiap kadar aspal dibuatkan benda uji dibuatkan sebanyak 3 sampel. Setelah melakukan tes Marshall, diketahui bahwa dengan volumetrik dan parameter Marshall menggunakan 3 sampel dari setiap kadar aspal, didapatkan hasil rata-rata pada perhitungan : VMA sebesar 17,68\%, VIM sebesar 4,46\%, VFB sebesar 74,87\%, Stabilitas sebesar 1152 $\mathrm{kg}$, Flow sebesar 2,47 mm, dan MQ sebesar $472 \mathrm{~kg} / \mathrm{mm}$. Dan dari hasil tes atau pengujian karakteristik Marshall, kadar aspal optimum yang dibutuhkan pada campuran laston AC-BC dengan menggunakan filler bubuk gypsum dan abu bata merah adalah sebesar 6,5\%.
\end{abstract}

Kata kunci : Laston, filler, bubuk gypsum, abu bata merah, karakteristik Marshall 


\section{PENDAHULUAN}

\subsection{Latar Belakang}

Jalan merupakan sarana yang dibuat atau dibangun untuk mempermudah transportasi melalui jalur darat, menghubungkan dua tempat atau lebih[1][2]. Jalan memiliki peranan yang sangat penting dalam meningkatkan perkembangan sosial, perekonomian,dan pembangunan nasional. Ada beberapa tahapan yang harus dilakukan pada saat pembangunan jalan, salah satunya adalah tahapan perkerasan jalan. Pada tahap ini, jalan diperkeras dengan menggunakan lapisan konstruksi yang mempunyaikekuatan, ketebalan, kekakuan,dan kestabilan tertentu supaya jalan dapat menyalurkan beban kendaraan yang melintas di atas permukaan jalan ke tanah bagian dasar dengan aman[3][4].

Lapis aspal beton terbuat dari agregat halus, agregat kasar, filler, dan bahan pengikat berupa aspal dengan kadar tertentu yang dicampur dalam kondisi masih panas. Berdasarkan ketentuan Kementrian Pekerjaan Umum Direktorat Jenderal Bina Marga 2010 Revisi 3[5], persyaratan filler yang harus dipenuhi adalah filler harus dalam kondisi kering, bebas dari gumpalan-gumpalan dan lolos ayakan No. 200[6]. Berdasarkan persyaratan tersebut, filler yang sering digunakan di lapangan adalah filler dengan bahan semen, karena semen mudah didapatkan di toko-toko bangunan. Namun hal tersebut tidak menutup kemungkinan untuk menggunakan filler dengan bahan yang lain selama bahan tersebut masih memenui persyaratan[7][8].

Pada penelitian ini, akan dicoba mengganti filler semen dengan menggunakan bahan bubuk gypsum yang dikombinasikan dengan abu bata merah[9][10]. Penggunaan agregat kasar dan filler pada laston banyak diteliti untuk mendapatkan kinerja campuran yang baik dan ekonomis [11]Penelitian ini merupakan eksperimen atau percobaan, dan akan dilihat pengaruhnya dari substitusi (penggantian) filler semen pada campuran aspal beton AC-BC dengan kadar yang bervariasi, yaitu 5\%, 5,5\%, 6\%, 6,5\%, dan $7 \%$.

\subsection{Rumusan Masalah}

Berdasarkan latar belakang di atas, maka dapat dirumuskan permasalahan/masalah yang akan diteliti sebagai berikut[12][13]:

1. Bagaimana hasil uji dari aspal beton dengan menggunakan filler 3,5\% bubuk gypsum dan 3,5\% abu bata merah pada alat Marshall?

2. Berapa kadar aspal optimum yang dihasilkan pada aspal beton dengan menggunakan filler $3,5 \%$ bubuk gypsum dan 3,5\% abu bata merah?

\subsection{Tujuan Penelitian}

1. Untuk mengetahui bagaimana hasil uji dari aspal beton dengan menggunakan filler 3,5\% bubuk gypsum dan 3,5\% abu bata merah pada alat Marshall. 
2. Untuk mengetahui berapa kadar aspal optimum yang dihasilkan pada aspal beton menggunakan filler 3,5\% bubuk gypsum dan 3,5\% abu bata merah.

\subsection{Batasan Masalah}

1. Perkerasan lentur yang direncanakanadalah aspal beton campuran panas.

2. Spesifikasi aspal menggunakan Spesifikasi Bina Marga 2010 Divisi 6 Revisi 3.

3. Pengujian benda uji menggunakan Marshall Test.

4. Kadar aspal yang digunakan dalam penelitian ini, yaitu 5\%, 5,5\%, 6\%, 6,5\%, dan 7\%.

5. Kadar filler yang digunakan adalah sebanyak $7 \%$ dengan menggunakan 2 bahan, yaitu $3,5 \%$ bubuk gypsum dan 3,5\% abu bata merah.

\subsection{Lokasi Penelitian}

Penelitian ini dilakukan di Laboratorium Fakultas Teknik, Universitas Kadiri, Kota Kediri.

\section{METODOLOGI PENELITIAN}

\subsection{Laston AC-BC (Asphalt Concrete-Binder Course)}

Asphalt Concrete Binder Course (AC-BC) adalah lapisan perkerasan yang terletak dibawah lapisan aus. Tidak berhubungan langsung dengan cuaca, tetapi perlu memiliki stabilitas untuk memikul beban lalulintas yang dilimpahkan oleh roda kendaraan. Sesuai dengan fungsi laston AC-BC juga disebut sebagai lapis pengikat[14]. AC-BC juga berfungsi sebagai perekat dalam campuran aspal beton yang sangat penting dipertahankan kemampuannya terhadap kelekatan dan titik kelenturannya[15][16].

Tabel 1. Ketentuan Sifat-sifat Campuran Laston

\begin{tabular}{|c|c|c|c|c|}
\hline \multirow{2}{*}{\multicolumn{2}{|c|}{ Sifat-sifat Campuran }} & \multicolumn{3}{|c|}{ Laston } \\
\hline & & \multirow{2}{*}{ Lapis Aus } & \multirow{2}{*}{\begin{tabular}{|l|} 
Lapis Antara \\
5
\end{tabular}} & \multirow{2}{*}{$\frac{\text { Pondasi }}{112}$} \\
\hline Jumlah tumbukan per bidang & & & & \\
\hline \multirow{2}{*}{$\begin{array}{c}\text { Rasio partikel lolosan ayakan } 0,075 \mathrm{~mm} \\
\text { dengan kadar aspal efektif }\end{array}$} & Min & \multicolumn{3}{|c|}{1,0} \\
\hline & Maks & \multicolumn{3}{|c|}{1,4} \\
\hline \multirow{2}{*}{ Rongga dalam campuran (\%) } & Min & \multicolumn{3}{|c|}{3,0} \\
\hline & Maks & \multicolumn{3}{|c|}{5,0} \\
\hline Rongga dalam agregat (VMA) (\%) & Min & 15 & 14 & 13 \\
\hline Rongga Terisi Aspal (\%) & Min & 65 & 65 & 65 \\
\hline Stabilitas Marshal $(\mathrm{Kg})$ & Min & \multicolumn{2}{|c|}{800} & 1800 \\
\hline \multirow{2}{*}{ Pelelehan (mm) } & Min & \multicolumn{2}{|c|}{2} & 3 \\
\hline & Maks & \multicolumn{2}{|c|}{4} & 6 \\
\hline $\begin{array}{l}\text { Stabilitas Marshall Sisa (\%) setelah } \\
\text { perendaman selama } 24 \text { jam, } 60^{\circ} \mathrm{C}\end{array}$ & Min & \multicolumn{3}{|c|}{90} \\
\hline $\begin{array}{l}\text { Rongga dalam campuran (\%) pada } \\
\text { kepadatan membal (refusal) }\end{array}$ & Min & \multicolumn{3}{|c|}{2} \\
\hline
\end{tabular}

Sumber : Spesifikasi Bina Marga 2010 Divisi 6 Revisi 3 


\subsection{Aspal}

Aspal merupakan instrumen utama yang dipakai untuk pembuatan jalan raya, material ini memiliki sifat fleksibilitas, stabilitas, durabilitas, dan tahan air[17]. Menurut (Sukirman, S. 2003), aspal adalah material yang pada temperatur ruang berbentuk padat sampai agak padat, dan bersifat termoplastis. Jadi, aspal akan mencair jika di panaskan sampai suatu temperatur tertentu, dan kembali membeku jika temperatur turun. Bersama dengan aggregat, aspal merupakan material pembentuk campuran perkerasan jalan. Banyak aspal dalam campuran perkerasan berkisar antara $4-10 \%$ berdasarkan berat campuran, atau $10-15 \%$ berdasarkan volume campuran.

Aspal mempunyai fungsi sebagai bahan perekat campuran material dan agregat, atau antara aspal itu sendiri, dan sebagai pengisi rongga pada agregat. Ada tiga jenis aspal, yaitu :

\section{Aspal Cair (Cut Back Asphalt) \\ 2. Aspal Keras (Asphalt Cement) \\ 3. Aspal Emulsi}

\subsection{Gradasi Agregat}

Gradasi Agregat adalah susunan butir agregat sesuai ukurannya. Ukuran butir dapat diperoleh melalui pemeriksaan analisa saringan. Gradasi agregat dinyatakan dalam presentase lolos atau tertahan, yang dihitung berdasarkan berat agregat (Sukirman, S. 2003).

Ada 3 macam gradasi agregat, yaitu:

1. Gradasi seragam (uniform graded)/gradasi terbuka (open graded)

2. Gradasi rapat (dense graded)

3. Gradasi senjang (gap graded)

Tabel 2. Spesifikasi Gradasi Campuran Beton Aspal

\begin{tabular}{|c|c|c|c|c|c|c|c|c|c|}
\hline \multirow{2}{*}{$\begin{array}{c}\text { Ukuran } \\
\text { Ayakan } \\
(\mathbf{m m})\end{array}$} & \multicolumn{6}{|c|}{ \% Berat Yang Lolos terhadap Total Agregat dalam Campuran } \\
\cline { 2 - 9 } & Latasir (SS) & \multicolumn{3}{|c|}{ Lataston (HRS } & \multicolumn{3}{|c|}{ Laston (AC) } \\
\cline { 2 - 9 } & Kelas A & Kelas B & WC & Base & WC & Base & WC & BC & Base \\
\hline 37,5 & & & & & & & & & 100 \\
\hline 25 & & & & & & & & 100 & $90-100$ \\
\hline 19 & 100 & 100 & 100 & 100 & 100 & 100 & 100 & $90-100$ & $76-90$ \\
\hline 12,5 & & & $90-100$ & $90-100$ & $87-100$ & $90-100$ & $90-100$ & $75-90$ & $60-78$ \\
\hline 9,5 & $90-100$ & & $75-85$ & $65-90$ & $55-88$ & $55-70$ & $77-90$ & $66-82$ & $52-71$ \\
\hline 4,75 & & & & & & & $53-69$ & $44-64$ & $35-54$ \\
\hline 2,36 & & $75-100$ & $50-72$ & $35-55$ & $50-62$ & $32-44$ & $33-53$ & $30-49$ & $23-41$ \\
\hline 1,18 & & & & & & & $21-40$ & $18-38$ & $13-30$ \\
\hline 0,600 & & & $35-60$ & $15-35$ & $20-45$ & $15-35$ & $14-30$ & $12-28$ & $10-22$ \\
\hline 0,300 & & & & & $15-35$ & $5-35$ & $9-22$ & $7-20$ & $6-15$ \\
\hline 0,150 & & & & & & & $6-15$ & $5-13$ & $4-10$ \\
\hline 0,075 & $10-15$ & $8-13$ & $6-10$ & $2-9$ & $6-10$ & $4-8$ & $4-9$ & $4-8$ & $3-7$ \\
\hline
\end{tabular}

Sumber : Spesifikasi Bina Marga 2010 Divisi 6 Revisi 3 


\subsection{Gipsum}

Gipsum adalah salah satu contoh mineral dengan kadar kalsium yang mendominasi pada mineralnya. Gipsum yang paling umum ditemukan adalah jenis hidrat kalsium sulfat dengan rumus kimia CaSO4.2H2O. Gipsum adalah salah satu dari beberapa mineral yang teruapkan. Contoh lain dari mineral-mineral tersebut adalah karbonat, borat, nitrat, dan sulfat. Mineralmineral ini diendapkan di laut, danau, gua dan di lapian garam karena konsentrasi ion-ion oleh penguapan. Ketika air panas atau air memiliki kadar garam yang tinggi, gipsum berubah menjadi basanit (CaSO4.H2O) atau juga menjadi anhidrit (CaSO4). Dalam keadaan seimbang, gipsum yang berada di atas suhu $108{ }^{\circ} \mathrm{F}$ atau $42{ }^{\circ} \mathrm{C}$ dalam air murni akan berubah menjadi anhidrit[18][19].

\subsection{Bata Merah}

Definisi batu bata menurut SNI 15-2094-2000, batu bata merupakan suatu unsur bangunan yang diperuntukkan konstruksi bangunan yang dibuat dari tanah dengan atau tanpa campuran bahan-bahan lain, dibakar cukup tinggi, hingga tidak dapat hancur lagi bila direndam dalam air[20][21].

\subsection{Metode Marshall}

Metode pengujian Marshall merupakan metode yang paling sering digunakan dan distandarisasikan dalam American Society for Testing and Material 1993[22][23]. Dalam metode pengujian Marshall tersebut terdapat tiga parameter penting, yaitu:

\section{Marshall Stability}

2. Marshall Flow

3. Marshall Quotient.

Marshall Quotient adalah nilai kekakuan berkembang SpeedoStiffnes, yang menunjukkan ketahanan campuran beton aspal terhadap deformasi tetap[24][25].

\subsection{Tempat Penelitian}

Penelitian ini dilakukan di Laboratorium Fakultas Teknik, Universitas Kadiri, Kota Kediri.

\subsection{Alat dan Bahan}

Peralatan yang digunakan adalah:

1. Alat Uji Pemeriksaan Agregat:
a. Mesin Los Angeles (Tes Abrasi)
b. Alat pengering (Oven)
c. Alat uji berat jenis
d. Timbangan.

2. Alat Uji Pemeriksaan Aspal 
3. Satu set saringan

4. Alat Uji Karakteristik Campuran Agregat dan Aspal:

a. Alat cetak benda uji berbentuk silinder

b. Marshall Automatic Compactor

c. Ejector

d. Bak Perendam yang dilengkapi pengatur suhu

e. Alat tekan Marshall

f. Alat-alat penunjang (kontainer)

Bahan-bahan campuran laston AC-BC adalah:

1. Agregat kasar, yaitu batu pecah yang didapatkan dari CV. Ageng Selo, Kec. Semen, Kab. Kediri

2. Agregat halus, yaitu pasir yang didapatkan di salah satu toko bangunan di Kab. Kediri

3. Bahan pengikat, yaitu aspal yang didapatkan PT. Triple S Putra Kediri, Kec. Grogol, Kab. Kediri

4. Bahan pengisi (filler), yaitu serbuk gypsum dan abu bata merah yang didapatkan dari limbah bahan bangunan di Kab. Kediri

\subsection{Prosedur Penelitian}

Tahapan dalam pelaksanaan penelitian ini adalah:

1. Pengujian pendahuluan

2. Pengumpulan material dan penyiapan alat-alat

3. Melakukan pemeriksaan awal terhadap bahanyang akan digunakan dalam penelitian

4. Merencanakan campuran aspal yang akan dibuat

5. Persiapan pembuatan benda uji Marshall

6. Membuat campuran atau benda uji

7. Melakukan pengujian Marshall

8. Analisi dan pembahasan

9. Menarik kesimpulan

\section{PEMBAHASAN}

\subsection{Gradasi Campuran}

Proporsi agregat gabungan diperoleh dari hasil perhitungan keausan agregat kasar (batu pecah) yang dijadikan sebagai penentu awal, apakah bahan campuran aspal beton tersebut layak atau tidak untuk digunakan. Setelah nilai keausan sudah terpenuhi $(<40 \%)$, nilai perbandingan komposisi rencana dikalikan dengan nilai persen lolos pada saat analisa saringan. 
Tabel 3. Penentuan Gradasi Campuran

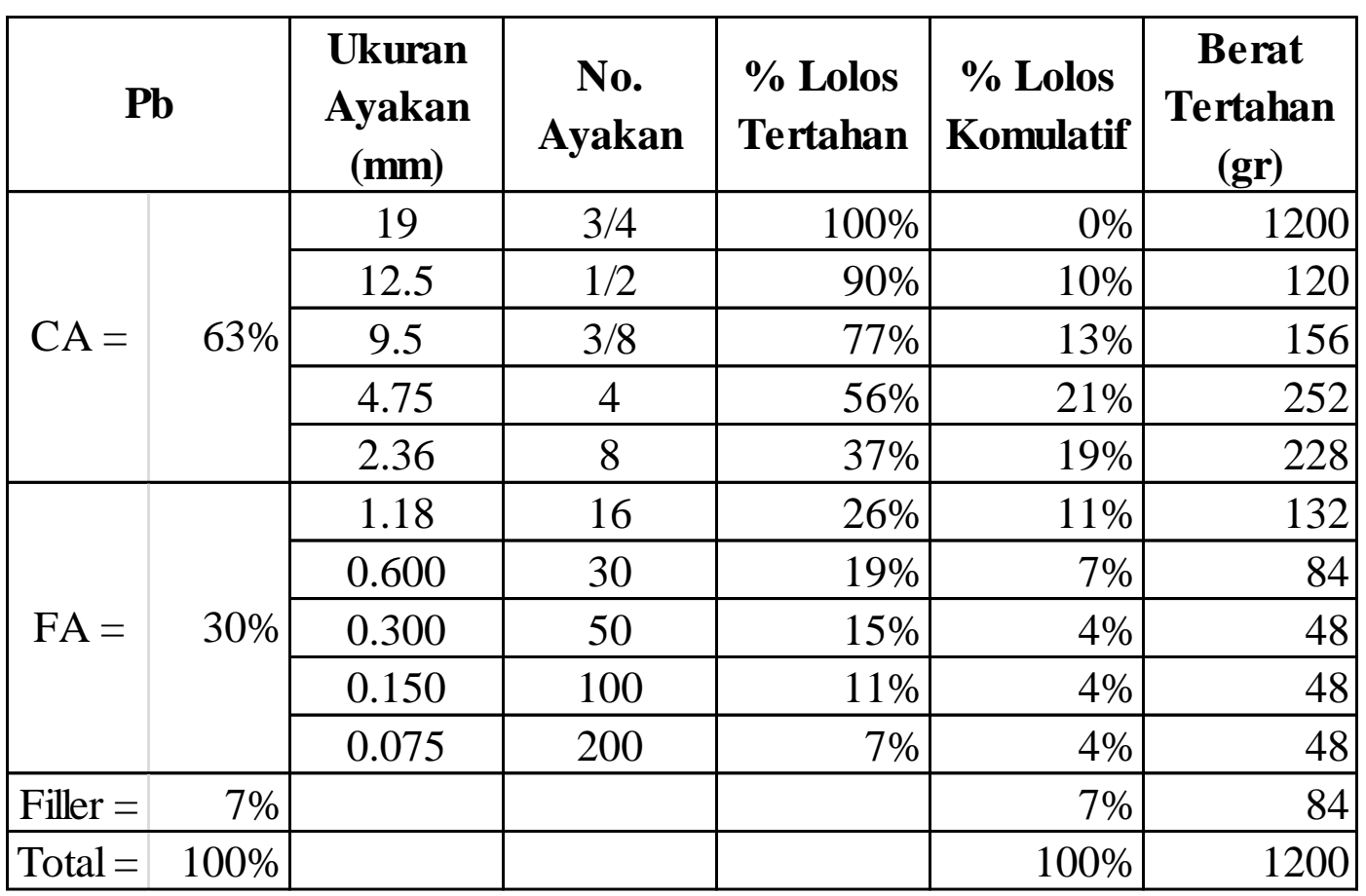

Sumber: hasil uji di lab teknik univ. kadiri

\subsection{Penentuan Kadar Aspal}

Kadar aspal yang akan digunakan harus sesuai dengan gradasi campuran yang direncanakan.

$$
\begin{array}{ll}
\mathrm{Pb} & =0,035(\% \mathrm{CA})+0,045(\% \mathrm{FA})+0,18(\% \text { filler })+\mathrm{K} \\
\mathrm{Pb} & =0,035(63 \%)+0,045(30 \%)+0,18(7 \%)+\mathrm{K} \\
\mathrm{Pb} & =5,815 \%>>6 \%
\end{array}
$$

Dengan demikian, variasi kadar aspal yang digunakan adalah:
a. $\mathrm{Pb}-1=5 \%$
b. $\mathrm{Pb}-0,5=5,5 \%$
c. $\mathrm{Pb}+0=6 \%$
d. $\mathrm{Pb}+0,5=6,5 \%$
e. $\mathrm{Pb}+1=7 \%$ 


\subsection{Hasil Pengujian Marshall}

Tabel 4. Hasil Pengujian Marshall Untuk Masing-Masing Sampel Per Kadar Aspal

\begin{tabular}{|c|l|c|c|c|c|c|c|}
\hline No & Kadar aspal & $\begin{array}{c}\text { VMA } \\
\%\end{array}$ & $\begin{array}{c}\text { VIM } \\
\%\end{array}$ & $\begin{array}{c}\text { VFB } \\
\%\end{array}$ & $\begin{array}{c}\text { Stabilitas } \\
\mathrm{kg}\end{array}$ & $\begin{array}{c}\text { Flow } \\
\mathrm{Mm}\end{array}$ & $\begin{array}{c}M Q \\
\mathrm{~kg} / \mathrm{mm}\end{array}$ \\
\hline & Aspal 5\% & & & & & & \\
\hline 1 & sampel 1 & 19,18 & 8,3 & 56,73 & 438 & 2,23 & 197 \\
\hline 2 & sampel 2 & 18,86 & 8,1 & 56,12 & 459 & 2,34 & 196 \\
\hline 3 & sampel 3 & 19,06 & 7,8 & 55,86 & 408 & 2,12 & 192 \\
\hline & Aspal 5,5\% & & & & & & \\
\hline 4 & sampel 1 & 17,47 & 5,87 & 66,40 & 1314 & 2,67 & 492 \\
\hline 5 & sampel 2 & 17,77 & 5,52 & 66,38 & 1302 & 2,7 & 482 \\
\hline 6 & sampel 3 & 17,02 & 5,26 & 66,43 & 1325 & 2,61 & 508 \\
\hline & Aspal 6\% & & & & & & \\
\hline 7 & sampel 1 & 17,98 & 5,94 & 66,96 & 1388 & 2,96 & 469 \\
\hline 8 & sampel 2 & 17,8 & 5,87 & 66,8 & 1413 & 2,9 & 487 \\
\hline 9 & sampel 3 & 17,66 & 5,9 & 66,58 & 1376 & 2,86 & 481 \\
\hline & Aspal 6,5\% & & & & & & \\
\hline 10 & sampel 1 & 17,31 & 4,66 & 73,08 & 1241 & 3,15 & 394 \\
\hline 11 & sampel 2 & 17,36 & 4,6 & 72,97 & 1265 & 3,17 & 399 \\
\hline 12 & sampel 3 & 17,33 & 4,68 & 73,15 & 1278 & 3,16 & 404 \\
\hline & Aspal 7\% & 15,67 & 5,75 & 69,08 & 925 & 3,33 & 278 \\
\hline 13 & sampel 1 & 5,72 & 69,09 & 857 & 3,36 & 255 \\
\hline 14 & sampel 2 & $3-5 \%$ & $65 \%<$ & $800 \mathrm{~kg}$ & $2-4 \mathrm{~mm}$ & $\mathrm{~min} 250$ \\
\hline 15 & sampel 3 & & & & & \\
\hline & Spesifikasi & 15,79 & 69,09 & 891 & 3,32 & 268 \\
\hline
\end{tabular}

Sumber: hasil perhitungan dan uji di lab teknik univ. Kadiri

Tabel 5. Hasil Pengujian Karakteristik Marshall Untuk Seluruh Parameter

\begin{tabular}{|c|c|c|c|c|c|c|c|}
\hline No. & Kadar Aspal & $\begin{array}{c}\text { VMA } \\
\%\end{array}$ & $\begin{array}{c}\text { VIM } \\
\%\end{array}$ & $\begin{array}{c}\text { VFB } \\
\%\end{array}$ & $\begin{array}{c}\text { Stabilitas } \\
\mathrm{kg}\end{array}$ & $\begin{array}{c}\text { Flow } \\
\mathrm{mm}\end{array}$ & $\begin{array}{c}\text { MQ } \\
\mathrm{kg} / \mathrm{mm}\end{array}$ \\
\hline & Sampel 1 & & & & & & \\
\hline 1 & $5 \%$ & 18.33 & 5.23 & 71.47 & 987 & 1.97 & 501 \\
\hline 2 & $5.50 \%$ & 17.84 & 4.77 & 73.26 & 1048 & 2.12 & 494 \\
\hline 3 & $6 \%$ & 17.58 & 4.24 & 75.88 & 1123 & 2.24 & 501 \\
\hline 4 & $6.50 \%$ & 17.23 & 3.87 & 77.54 & 1174 & 2.63 & 446 \\
\hline
\end{tabular}




\begin{tabular}{|c|c|c|c|c|c|c|c|}
5 & $7 \%$ & 17.04 & 3.47 & 79.64 & 1213 & 2.95 & 411 \\
\hline & Sampel 2 & & & & & & \\
\hline 6 & $5 \%$ & 18.38 & 5.36 & 70.84 & 1024 & 2.06 & 497 \\
\hline 7 & $5.50 \%$ & 17.9 & 4.85 & 72.91 & 1122 & 2.18 & 515 \\
\hline 8 & $6 \%$ & 17.64 & 4.39 & 75.11 & 1178 & 2.31 & 510 \\
\hline 9 & $6.50 \%$ & 17.3 & 4.02 & 76.76 & 1202 & 2.7 & 445 \\
\hline 10 & $7 \%$ & 17.12 & 3.52 & 79.44 & 1243 & 3.12 & 398 \\
\hline & Sampel 3 & & & & & & \\
\hline 11 & $5 \%$ & 18.45 & 5.42 & 70.62 & 1047 & 2.14 & 489 \\
\hline 12 & $5.50 \%$ & 18.11 & 5.14 & 71.62 & 1175 & 2.25 & 522 \\
\hline 13 & $6 \%$ & 17.72 & 4.53 & 74.44 & 1212 & 2.39 & 507 \\
\hline 14 & $6.50 \%$ & 17.39 & 4.31 & 75.22 & 1244 & 2.78 & 447 \\
\hline 15 & $7 \%$ & 17.22 & 3.74 & 78.28 & 1289 & 3.25 & 397 \\
\hline & Spesifikasi & $15 \%<$ & $3-5 \%$ & $65 \%<$ & $800 \mathrm{~kg}$ & $\begin{array}{c}2-4 \\
\mathrm{~mm}\end{array}$ & min 250 \\
\hline
\end{tabular}

Sumber: hasil perhitungan dan uji di lab teknik univ. Kadiri

\subsection{Analisis Penentuan Kadar Aspal Optimum}

Darihasil pengujian karakteristik Marshallpada campuran laston AC-BC menggunakan filler bubuk gypsum dan abu bata merah, kadar aspal optimum yang dibutuhkan adalah sebesar 6,5\%. Analisis penentuan Kadar Aspal Optimum campuran aspal panas mengacu pada persyaratan Spesifikasi Umum 2010Divisi 6 tentang perkerasan Aspal dan SNI 06-2489-1991 (Cara Uji Campuran Beraspal Panas dengan Metode Marshall) ditunjukkan pada tabel berikut:

Tabel 6. Analisis Penentuan Kadar Aspal Optimum

\begin{tabular}{|c|c|c|c|c|c|c|c|}
\hline \multirow{2}{*}{ No. } & \multirow{2}{*}{$\begin{array}{c}\text { Parameter } \\
\text { Marshall }\end{array}$} & \multirow{2}{*}{ Spesifikasi } & \multicolumn{5}{|c|}{ Kadar Aspal Minyak $(\%)$} \\
\hline & & & 5 & 5,5 & 6 & 6,5 & 7 \\
\hline 1 & $\operatorname{VIM}(\%)$ & $3-5$ & & & & & \\
\hline 2 & $\operatorname{VMA}(\%)$ & $>15$ & & & & & \\
\hline 3 & $\operatorname{VFB}(\%)$ & $>65$ & & & & & \\
\hline 4 & Stabilitas $(\mathrm{Kg})$ & $>800$ & & & & & \\
\hline 5 & Flow(mm) & $2-4$ & & & & & \\
\hline 6 & $M Q(\mathrm{Kg} / \mathrm{mm})$ & $>250$ & & & & & \\
\hline 7 & $\mathrm{KAO}$ & & & & & $0,50 \%$ & \\
\hline
\end{tabular}

Sumber: pembacaan grafik dan perhitungan 


\section{KESIMPULAN DAN SARAN}

\subsection{Kesimpulan}

Dari pembahasan dan analisis hasil pengujian pada bab empat, maka dapat saya simpulkan bahwa:

1. Dari penelitian yang sudah dilakukan dengan volumetrik dan parameter Marshall menggunakan 3 sampel dari setiap kadar aspal, yaitu 5\%, 5,5\%, 6\%, 6,5\%, dan 7\%, didapatkan hasil rata-rata pada perhitungan VMA sebesar 17,68\%, VIM sebesar 4,46\%, VFB sebesar 74,87\%, Stabilitas sebesar $1152 \mathrm{~kg}$, Flow sebesar 2,47 mm, dan MQ sebesar $472 \mathrm{~kg} / \mathrm{mm}$.

2. Berdasarkan hubungan antara kandungan kadar aspal, seluruh parameter Marshall sertavolumetrik menggunakan filler bubuk gypsum dan abu bata merah, dapat saya disimpulkan bahwa kandungan kadar aspal optimum berada pada kadar aspal 6,5\%.

\subsection{Saran}

Karena penelitian ini merupakan percobaan pengujian di laboratorium, maka diperlukan ketelitian dalam pengukuran bahan-bahan dan pembacaan data-data yang dihasilkan, penimbangan bahan dan material, dan pembacaan alat-alat supaya dapat menghasilkan data-data yang baik dan benar.

\section{UCAPAN TERIMAKASIH}

Dalam penyusunan artikel ini, penulis ucapkan terimakasih kepada dosen pembimbing dan Universitas Kadiri. Penulis berharap agar artikel ini dapat bermanfaat bagi pembaca.

\section{DAFTAR PUSTAKA}

[1] R. Yuwono, Y. C. Sp, and L. D. K, "STUDY ANALISA VOLUME KENDARAAN PADA SIMPANG BERSINYAL DI PEREMPATAN ALUN ALUN KOTA KEDIRI," Jurmateks, vol. 1, no. 1, pp. 101-111, 2018.

[2] E. Nurfadzilah, S. Winarto, and Y. Cahyo, "ANALISA JALAN RING ROAD NGAWI STA 3+200 - STA 6+200 KABUPATEN NGAWI PROPINSI JAWA TIMUR,” Jurmateks, vol. 1, no. 1, pp. 33-43, 2018.

[3] D. D. B. Marga, "Tata Cara Perencanaan Geometrik Jalan Antar Kota," Dirjen DPU Bina Marga, 1997.

[4] D. P. U. SKBI-2.3. 26. 1987, UDC: 625.73 (02), "Petunjuk Perencanaan Komponen Tebal Perkerasan Lentur Jalan Raya Dengan Metode Analisa Jalan,” Peratur. Perenc. Geom. Jalan Raya, no. 13, 1970.

[5] B. Marga, "Tata Cara Perencanaan Geometrik Jalan Antar Kota," Direktorat Pembin. Jalan Kota. Jakarta, 1997. 
[6] J. McNulty, "PEMANFAATAN LIMBAH BETON SEBAGAI PENGGANTI AGREGAT KASAR PADA CAMPURAN ASPHALT CONCRETE-WEARING COURSE GRADASI KASAR Arys," vol. 66, no. 1997, pp. 37-39, 2013.

[7] S. L. Hendarsin, "Perencanaan Teknik Jalan raya," Politek. Negeri Bandung, 2000.

[8] S. E. Raya, P. Priyo, and H. Dwi, "Variasi Temperatur Pencampuran Terhadap Parameter Marshall pada Campuran Lapis Aspal Beton,” Jrsdd, vol. 3, no. 3, pp. 455$468,2015$.

[9] H. Fithra, "PENGARUH JUMLAH TUMBUKAN PADA CAMPURAN ASPHALT CONCRETE WEARING COURSE (AC-WC) TAMBAHAN LATEKS TERHADAP SIFAT MARSHALL," Teras J., 2017.

[10] R. T. Bethary and M. F. Pradana, "PERENCANAAN GEOMETRIK JALAN ALTERNATIF PALIMA-CURUG ((Studi Kasus: Kota Serang),” J. Fondasi, vol. 5, no. $2,2016$.

[11] M. Zaenuri, R. Romadhon, and A. Gunarto, "Penelitian Penggunaan Batu Gamping Sebagai Agregat Kasar Dan Filler Pada Aspal Campuran Ac-Bc,” UKaRsT, vol. 2, no. 1, p. 26, 2018, doi: 10.30737/ukarst.v2i1.357.

[12] A. Badrujaman, "Perencanaan Geometrik Jalan Dan Anggaran Biaya Ruas Jalan Cempaka - Wanaraja Kecamatan Garut Kota," J. Konstr., vol. 14, no. 1, pp. 25-34, 2016.

[13] Departemen Pekerjaan Umum, "Petunjuk Perencanaan Tebal Perkerasan Lentur Jalan Raya Dengan Metode Analisa Komponen," 1987.

[14] Departemen Pekerjaan Umum, Metode AASTHO 1972. Jakarta: Yayasan Badan Penerbit PU, 1972.

[15] S. Sukirman, Perkerasan Lentur Jalan Raya. Bandung, 1993.

[16] A. Kholiq, "Perencanaan Tebal Perkerasan Lentur Jalan Raya Antara Bina Marga Dan Aashto'93 (Studi Kasus: Jalan Lingkar Utara Panyingkiran-Baribis Ajalengka),” JEnsitec, vol. 1, no. 01, pp. 43-51, 2014, doi: 10.31949/j-ensitec.v1i01.15.

[17] S. Anam, "PENGUJIAN PERKERASAN ASPAL PORUS DENGAN PENAMBAHAN TREAD BAN BEKAS PADA UJI MARSHALL," UKaRsT, vol. 2, no. 2, pp. 59-69, 2018.

[18] D. P. Umum, "Metode pengujian campuran aspal dengan alat Marshall," SNI 06-24891991, 1991.

[19] S. Sukarman, Beton Aspal Campuran Panas. Yayasan Obor Indonesia, 2003.

[20] D. J. B. Marga, "Departemen Pekerjaan Umum," Man. Kapasitas Jalan Indones. (MKJI 1997), Jakarta, 1997. 
[21] M. AASTHO, "M 20-70 (2002) dan Revisi SNI 03-1737-1989," Spesifikasi AASHTO dan SNI untuk berbagai nilai penetrasi aspal.

[22] Dinas Pekerjaan Umum Direktorat Jenderal Bina Marga, Manual Perkerasan Jalan Dengan Alat Benkelmen Beam No. 01/MN/BM/83. Jakarta: Yayasan Badan Penerbit PU, 1983.

[23] Direktorat Jendral Bina Marga, "R s 2010-2014,” 2014.

[24] Didik Purwadi, Buku Ajar Perkerasan Jalan. Semarang, 2008.

[25] D. P. Umum, "SNI 06-2456-1991 Metode Pengujian Penetrasi Bahan-Bahan Bitumen." Badan Penelitian dan Pengembangan PU, 1991. 